$46.3 \%$ of GLM pts and $40.6 \%$ of PBO pts had $>1 \mathrm{AE} ; 2.9 \%$ vs. $3.3 \%$ of pts, respectively, had $\geq 1$ serious $A E$. Two deaths, 2 malignancies, and 1 demyelinating event were reported. The most common treatment-emergent type of AE was infection $(20.0 \%$ of GLM pts vs. $13.8 \%$ of PBO pts). No opportunistic infection or tuberculosis was reported through wk24. The rate of infusion reactions was low at $<2 \%$; none was serious or severe.

\begin{tabular}{|c|c|c|c|}
\hline & Placebo & Golimumab $2 \mathrm{mg} / \mathrm{kg}$ & P-values \\
\hline Patients randomized, $\mathrm{n}$ & 239 & 241 & \\
\hline \multicolumn{4}{|l|}{ Clinical efficacr at wk14 } \\
\hline ACR20/50/70, (\%) & $21.8 / 6.3 / 2.1$ & $75.1 / 43.6 / 24.5$ & $p<0.001$ \\
\hline PASI $75, \mathrm{n}(\%)^{*}$ & $27 / 198(13.6 \%)$ & $116 / 196(59.2 \%)$ & $p<0.001$ \\
\hline Change from $\mathrm{BL}$ in HAQ-DI (n) & 222 & 233 & \\
\hline Mean (SD) & $-0.12(0.47)$ & $-0.60(0.53)$ & $p<0.001$ \\
\hline Change from BL in enthesitis** (n) & 173 & 182 & \\
\hline $\operatorname{Mean}(\mathrm{SD})$ & $-0.8(1.98)$ & $-1.87(1.75)$ & $p<0.001$ \\
\hline Change from $\mathrm{BL}$ in dactylitis** (n) & 115 & 130 & \\
\hline Mean (SD) & $-2.8(7.03)$ & $-7.8(8.57)$ & $p<0.001$ \\
\hline Minimal Disease Activity, $\mathrm{n} N(\%)$ & $10 / 239(4.2 \%)$ & $65 / 241(27.0 \%)$ & $\mathrm{p}<0.001$ \\
\hline Number Needed to Treat $(95 \% \mathrm{CI})$ & & $1.9(1.64,2.18)$ & \\
\hline \multicolumn{4}{|l|}{ Clinical efficacy at Week 24} \\
\hline ACR $50, n(\%)$ & $15(6.3 \%)$ & $129(53.5 \%)$ & \\
\hline \multicolumn{4}{|l|}{ Imaging data at Week 24} \\
\hline Change from $\mathrm{BL}$ in vdH-S score $\mathrm{C}$ & 237 & 237 & \\
\hline \multicolumn{4}{|l|}{ HRQoL at wk14 } \\
\hline Change from BL in SF-36 PCS score & 222 & 233 & \\
\hline & $\frac{69(5.92)}{202}$ & $\frac{8.65(7.60)}{233}$ & $p<0.001$ \\
\hline $\begin{array}{r}\text { Change from BL in SF-36 MCS score (n) } \\
\text { Mean (SD) }\end{array}$ & $\begin{array}{ll}222 \\
0.97(7.64)\end{array}$ & $\begin{array}{c}233 \\
5.33(9.95)\end{array}$ & $\mathrm{p}<0.001$ \\
\hline
\end{tabular}

Conclusions: In pts with active PsA, IV GLM demonstrated significant and clinically meaningful improvements of disease activity and physical function, skin psoriasis clearance, $\mathrm{HRQ}$ oL, reduction in dactylitis and enthesitis, and inhibition of structural damage progression. GLM was well-tolerated through wk24; the safety profile was consistent with other anti-TNF therapies, including SC GLM.

Disclosure of Interest: A. Kavanaugh Consultant for: Janssen, M. E. Husni Consultant for: Janssen, UCB, Amgen, Novartis, Lilly, Regeneron, D. Harrison Employee of: Janssen Research \& Development, LLC, L. Kim Employee of: Janssen Research \& Development, LLC, K. H. Lo Employee of: Janssen Research \& Development, LLC, E. Hsia Employee of: Janssen Research \& Development, LLC

DOI: 10.1136/annrheumdis-2017-eular.1165

\section{FRI0487 APREMILAST IS ASSOCIATED WITH LONG-TERM (4-YEAR) DAS-28 (CRP) REMISSION AND IMPROVEMENTS IN SKIN DISEASE: RESULTS FROM A PHASE III STUDY IN DMARD/BIOLOGIC-EXPERIENCED PATIENTS WITH ACTIVE PSORIATIC ARTHRITIS}

C.J. Edwards ${ }^{1}$, F.J. Blanco ${ }^{2}$, J. Crowley ${ }^{3}$, M. Mcllraith ${ }^{4}$, M. Paris ${ }^{4}$, N. Delev ${ }^{4}$ L. Teng ${ }^{4}$, C.A. Birbara ${ }^{5} .{ }^{1}$ University Hospital Southampton, Southampton, United Kingdom; ${ }^{2}$ INIBIC-Hospital Universitario A Coruña, Galicia, Spain; ${ }^{3}$ Bakersfield Dermatology, Bakersfield; ${ }^{4}$ Celgene Corporation, Summit;

${ }^{5}$ University of Massachusetts Medical School, Worcester, United States

Background: Treatment goals for long-term control of skin and joint symptoms in active psoriatic arthritis (PsA) include clinically important changes in DAS-28 (CRP), achievement of remission in DAS-28 (CRP), reduction in swollen joint count (SJC), and decrease in skin disease. ${ }^{1}$ PALACE 3 included PsA patients with active joint disease and an active skin lesion at the time of enrollment.

Objectives: Report the impact of apremilast (APR) on PsA manifestations over 4 years.

Methods: Patients were stratified by baseline (BL) DMARD use (yes/no) and psoriasis involvement of the body surface area $(<3 \% />3 \%)$ and randomized (1:1:1) to placebo (PBO), APR $30 \mathrm{mg}$ BID (APR30), or APR $20 \mathrm{mg}$ BID (APR20). After the 24-week PBO-controlled phase, all patients were treated with APR30 or APR20 and could enroll in the long-term extension. Efficacy assessments were conducted through Week 208.

Results: 505 patients were randomized and received $>1$ dose of study medication (PBO: $n=169$; APR30: $n=167$; APR20: $n=169$ ). A total of $91 \%$ (227/249) of patients starting the fourth year of APR therapy completed the Week 208 visit. Patients treated with APR30 demonstrated sustained decreases in disease activity at Week 208, as shown by mean change from BL in DAS-28 (CRP) of $-1.66 ; 80.3 \%$ achieved good/moderate EULAR response and $50.4 \%$ achieved DAS-28 (CRP) remission. Sustained effect on inflammation at Week 208 was also demonstrated by mean/median percent changes in SJC, a marker of inflammatory activity, of $-77.4 \% /-100.0 \%$ (Table); $64.8 \%$ of patients had an SJC of 0 or 1 . Decreases in disability and maintenance of functionality were shown by sustained improvements in Health Assessment Questionnaire-Disability Index (HAQ-DI) scores (Table). A continued effect on skin disease was shown by decreases in skin involvement, as measured by the Psoriasis Area and Severity Index (PASI); $54.7 \%$ of APR30 patients had BL PASI $>5$ and $27.3 \%$ had BL PASI $>10$; at Week 208, 64.5\% had PASI $<3$ and $77.4 \%$ had PASI $\leq 5$. PASI-75 and PASI-50 response rates also demonstrated clinically significant relief (Table). In patients treated with APR20, similar findings were observed at Week 208. No new safety concerns were identified through 208 weeks of APR30 therapy. During Weeks $>156$ to $\leq 208$ of APR30 exposure, the only adverse event (AE) occurring in $>5 \%$ of patients was nasopharyngitis; most AEs were mild or moderate in severity. Serious AEs occurred in $7.2 \%$ of APR30 patients over Weeks $>156$ to $\leq 208$, similar to rates in earlier study periods. Few discontinuations due to AEs $(0.7 \%)$ occurred over Weeks $>156$ to $\leq 208$. The APR20 safety profile was similar to that of APR30.

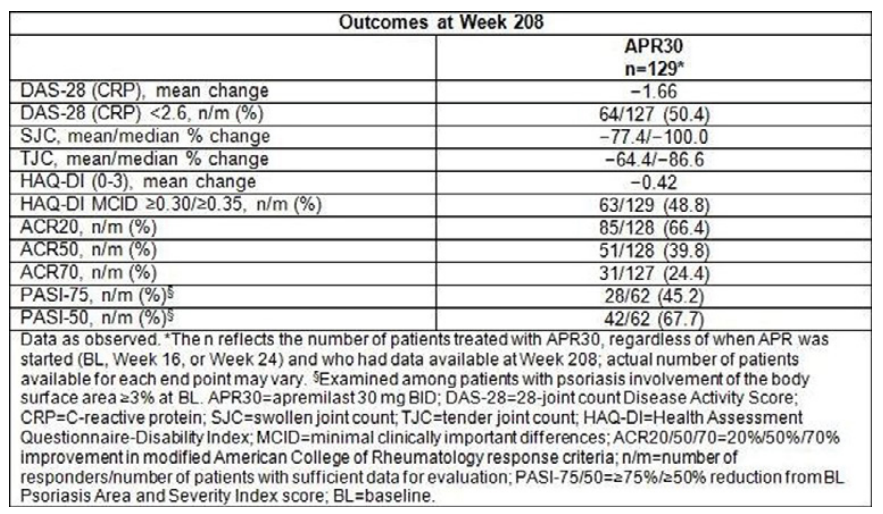

Conclusions: Over 208 weeks, APR demonstrated sustained and clinically important improvements in PsA signs and symptoms, including physical function and associated psoriasis, among patients continuing the study. APR was generally well tolerated with an acceptable safety profile.

References:

[1] Gossec L, et al. Ann Rheum Dis. 2016:75:499-510.

Disclosure of Interest: C. Edwards Grant/research support from: Celgene Corporation, Pfizer, Roche, Samsung, Consultant for: Celgene Corporation, Pfizer, Roche, Samsung, Speakers bureau: Abbott, GSK, Pfizer, Roche, F. Blanco Consultant for: Bioibérica, Gebro Pharma, Pfizer, J. Crowley Grant/research support from: AbbVie, Amgen, Celgene Corporation, Janssen, Merck, Pfizer, Consultant for: AbbVie, Amgen, Speakers bureau: AbbVie, M. Mcllraith Employee of: Celgene Corporation, M. Paris Employee of: Celgene Corporation, N. Delev Employee of: Celgene Corporation, L. Teng Employee of: Celgene Corporation, C. Birbara Grant/research support from: Amgen, BMS, Incyte, Eli Lilly, Merck, Pfizer

DOI: 10.1136/annrheumdis-2017-eular.3563

\section{FRI0488 PSORIATIC ARTHRITIS IN THE UNITED STATES: INCREASING ALL-CAUSE HOSPITALIZATIONS 1993-2014}

G. Singh ${ }^{1}$, C. Moise $^{2}$, A. Mithal ${ }^{3}$, R. lonescu ${ }^{2}$, A. Mithal ${ }^{4} .{ }^{1}$ Gastroenterology and Hepatology, Stanford University, Palo Alto, United States; ${ }^{2}$ Disciplina

Medicina Interna si Reumatologie, Spitalul Clinic "Sf. Maria", Bucharest,

Romania; ${ }^{3}$ Student; ${ }^{4}$ Epidemiology, ICORE, Woodside, United States

Background: Psoriatic arthritis (PsA) is a rare disease, with an estimated prevalence of $0.02-0.42 \%$ in Europe and US (1). PsA is often regarded as a mild disease, but recent data suggest an increase in comorbidities and mortality, possibly related to systemic inflammation (1).

Objectives: To study all-cause hospitalizations in patients with PsA in the United States (US) from 1993 to 2014.

Methods: The Nationwide Inpatient Sample (NIS) is a stratified random sample of all US community hospitals. It is the only US national hospital database with information on all patients, regardless of payer, including persons covered by Medicare, Medicaid, private insurance, and the uninsured. We examined all inpatient hospitalizations in NIS from 1993 to 2014 with a primary or secondary diagnosis of PsA, and compared them to total all-cause US hospitalizations during the same period. US population estimates and projections for the resident US population were obtained from the US Census Bureau.

Results: There were 789.8 million all-cause hospitalizations in 6.4 billion personyears of observation from 1993 to 2014 (123.4 hospitalizations per 1,000 person-years). During this time-period, 332,496 hospitalizations occurred in patients with PsA (5.2 per 100,000 person-years). All-cause US hospitalizations increased from 33.7 million in 1993 to 35.4 million in 2014, an increase of $4.8 \%$ over 22 years (Figure, dotted blue line). All-cause hospitalizations in PsA patients have increased from 6,866 in 1993 (2.6 per 100,000 person-year) to 33,875 in 2014 (10.6 per 100,000 person-years, a dramatic increase of over $393 \%$ ( $p<0.0001$, Figure solid red line). In 2014, hospitalizations in PsA patients accounted for 163,630 hospital days at a total national cost of over US $\$ 1.66$ billion.

Conclusions: All-cause hospitalizations in patients with PSA in the US have significantly increased by $393 \%$ in the last 22 years, almost 80 -fold of the $4.8 \%$ increase in US population all-cause hospitalization rate in the same time-period. This calls for an increase need for identification and management of serious co-morbid conditions in patients with PsA. 


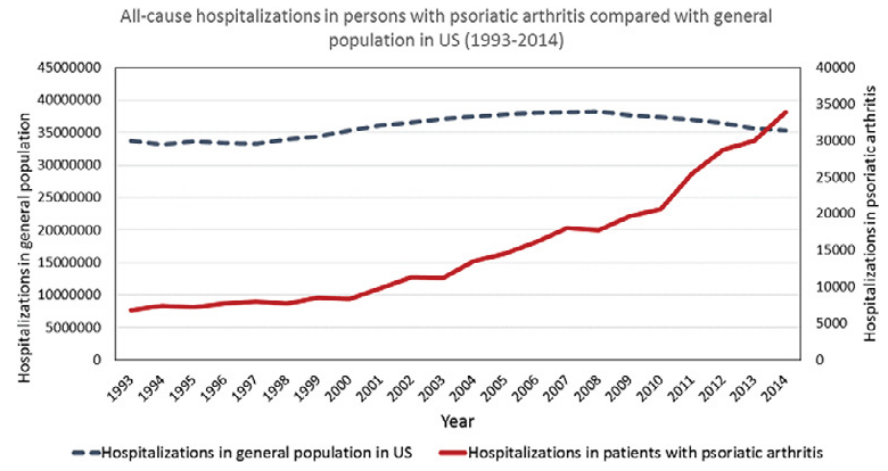

References:

[1] J Gelfand, D Gladman et al. Epidemiology of Psoriatic Arthritis in the Population of the United States. J Am Acad Dermatology, vol 53, p 573-577.

Disclosure of Interest: None declared

DOI: 10.1136/annrheumdis-2017-eular.5502

\section{FRI0489 CERTOLIZUMAB PEGOL IS ASSOCIATED WITH LONG-TERM IMPROVEMENTS IN PATIENT-REPORTED OUTCOMES IN PSORIATIC ARTHRITIS: 4-YEAR OUTCOMES FROM THE RAPID-PSA STUDY}

D. Gladman ${ }^{1}$, R. Fleischmann ${ }^{2}$, K. Harris ${ }^{3}$, L. Peterson ${ }^{4}$, P.J. Mease ${ }^{5}$.

${ }^{1}$ University of Toronto and Krembil Research Institute, Toronto Western Hospital, Toronto, Canada; ${ }^{2}$ UT Southwestern Medical Center and Dallas Metroplex Clinical Research Center, Dallas, United States; ${ }^{3}$ UCB Pharma, Brussels, Belgium; ${ }^{4}$ UCB Pharma, Raleigh; ${ }^{5}$ Swedish Medical Center and University of Washington, Seattle, United States

Background: Psoriatic arthritis (PSA) is a heterogeneous inflammatory disease that has a substantial impact on patients' (pts) physical and emotional wellbeing. ${ }^{1}$ Certolizumab pegol (CZP) is an Fc-free, PEGylated anti-TNF that has been shown to improve patient-reported outcomes (PROs) in pts with PsA over 96 weeks (wks) of treatment in the RAPID-PsA study (NCT01087788). ${ }^{2}$

Objectives: To investigate whether initial improvements in PROs observed with CZP treatment were maintained over 4 years in the RAPID-PsA study.

Methods: RAPID-PsA was double-blind and placebo-controlled to Wk24, doseblind to Wk48, and open-label to Wk216. Pts were aged $>18$ years, with a diagnosis of active PsA, and had failed treatment with $\geq 1$ DMARD. Pts originally randomized to CZP (400mg at Wks0,2,4 [loading dose] followed by either $200 \mathrm{mg}$ every 2 wks [Q2W] or $400 \mathrm{mg}$ every 4 wks [Q4W]) continued on their assigned dose during the open-label period. PROs assessed included Patient's Global Assessment of Arthritis Pain (PtAAP; visual analog scale), fatigue (numeric rating scale), Health Assessment Questionnaire-Disability Index (HAQ-DI), Short Form-36 Physical and Mental Component Summary (SF-36 PCS/MCS), Psoriatic Arthritis Quality of Life (PsAQoL), and Dermatology Life Quality Index (DLQI; assessed in the subgroup of pts with $\geq 3 \%$ body surface area affected by psoriasis at baseline [BL]). Data are reported as the mean change from BL (CFB) for pts randomized to CZP at WkO, with last observation carried forward (LOCF) imputation for Wk24, and LOCF imputation and observed case (OC) values for Wk216.

Results: Of 273 pts randomized to CZP at Wk0, $248(91 \%)$ completed Wk24 and $183(67 \%)$ completed Wk216. Improvements observed to Wk24 of treatment were generally maintained over 4 years (to Wk216) in all PROs assessed, regardless of prior anti-TNF exposure (Table). Similar improvements were observed in both CZP dose regimens for all PROs examined, including PtAAP (CFB at Wk216 in the 200mg Q2W group [with LOCF imputation]: -30.5, in the 400mg Q4W group: -33.8); fatigue (-2.3, -2.3); HAQ-DI (-0.50, -0.49); SF-36 PCS (8.73, 8.77); SF-36 MCS (3.91, 3.28); PsAQoL (-4.6, -4.4); and DLQI (-8.4, -6.8).

Conclusions: Early improvements with CZP treatment were maintained over 4 years in all PROs assessed in the RAPID-PsA study. Similar improvements were observed in pts with and without prior anti-TNF exposure, and in both CZP dose regimens.

References:

[1] Rosen C. Rheumatology 2012;51(3):571-6.

[2] Gladman D. Value in Health 2014;17(7):A386.

Acknowledgements: This study was funded by UCB Pharma. We thank the patients and their caregivers in addition to the investigators and their teams who contributed to this study. Editorial services were provided by Costello Medical Consulting.

Disclosure of Interest: D. Gladman Grant/research support from: Abbott, BristolMyers Squibb, Celgene, Johnson \& Johnson, MSD, Novartis, Pfizer, UCB Pharma, Consultant for: Abbott, Bristol-Myers Squibb, Celgene, Johnson \& Johnson, MSD, Novartis, Pfizer, UCB Pharma, R. Fleischmann Grant/research support from: Genentech Inc, Roche, Abbott, Amgen, UCB Pharma, Pfizer, Bristol-Myers Squibb, Lilly, Sanofi-Aventis, MSD, Novartis, AstraZeneca, Janssen, Consultant for: Roche, Abbott, Amgen, UCB Pharma, Pfizer, Bristol-Myers Squibb, Lilly,
Table: Mean change from baseline in patient-reported outcomes at Weeks 24 and 216 in patients with or without prior anti-TNF exposure

\begin{tabular}{|c|c|c|c|c|c|c|c|c|c|}
\hline & \multicolumn{3}{|c|}{$\begin{array}{l}\text { Patients with prior } \\
\text { anti-TNF exposure } \\
\text { CZP dose oombined } \\
(n=54)\end{array}$} & \multicolumn{3}{|c|}{$\begin{array}{c}\text { Patients without prior } \\
\text { anti-TNF exposure } \\
\text { CZP dose oombined } \\
(n=219)\end{array}$} & \multicolumn{3}{|c|}{$\begin{array}{c}\text { Overall } \\
\text { CZP dose combined } \\
\text { (N=273) }\end{array}$} \\
\hline & $\begin{array}{l}\text { Wk24 } \\
\text { (LOCF) }\end{array}$ & $\begin{array}{l}\text { Wk216 } \\
\text { (LOCF) }\end{array}$ & $\begin{array}{l}\text { Wk216 } \\
(\mathrm{OC}) \\
{[\mathrm{n}=34]}\end{array}$ & $\begin{array}{l}\text { Wk24 } \\
\text { (LOCF) }\end{array}$ & $\begin{array}{l}\text { Wk216 } \\
\text { (LOCF) }\end{array}$ & $\begin{array}{l}\text { Wk216 } \\
\text { (OC) } \\
{[n=151]}\end{array}$ & $\begin{array}{l}\text { Wk24 } \\
\text { (LOCF) }\end{array}$ & $\begin{array}{l}\text { Wk216 } \\
\text { (LOCF) }\end{array}$ & $\begin{array}{c}\text { Wk216 } \\
\text { (OC) } \\
{[n=185]}\end{array}$ \\
\hline \multicolumn{10}{|l|}{ Outcome } \\
\hline Pain (PtAAP) [a] & -33.3 & -34.6 & -44.2 & -27.3 & -31.5 & -35.9 & -28.5 & -32.1 & -37.4 \\
\hline Fatigue [b] & -2.1 & -2.0 & -2.5 & -2.0 & -2.3 & $\begin{array}{c}-2.8 \\
{[n=147]}\end{array}$ & -2.0 & -2.3 & $\begin{array}{c}-2.7 \\
{[n=181]}\end{array}$ \\
\hline HAQ-DI [o] & -0.60 & -0.59 & -0.67 & -0.45 & -0.47 & -0.54 & -0.48 & -0.50 & -0.57 \\
\hline SF-36 PCS [d] & 8.37 & 9.79 & $\begin{array}{c}11.18 \\
{[n=33]}\end{array}$ & 7.92 & 8.50 & $\begin{array}{c}9.64 \\
{[n=148]}\end{array}$ & 8.01 & 8.75 & $\begin{array}{c}9.92 \\
{[n=181]}\end{array}$ \\
\hline SF-36 MCS $[e]$ & 4.57 & 2.38 & $\begin{array}{c}5.29 \\
{[n=33]}\end{array}$ & 4.49 & 3.90 & $\begin{array}{c}5.36 \\
{[n=148]}\end{array}$ & 4.50 & 3.60 & $\begin{array}{c}5.35 \\
{[n=181]}\end{array}$ \\
\hline$P \frown A Q \circ L[f]$ & -4.1 & -4.2 & -5.1 & -3.8 & -4.6 & $\begin{array}{c}-5.1 \\
{[n=150]}\end{array}$ & -3.9 & -4.5 & $\begin{array}{c}-5.1 \\
{[n=184]}\end{array}$ \\
\hline DLQI [g] & $\begin{array}{c}-9.0 \\
{[n=36]}\end{array}$ & $\begin{array}{c}-8.1 \\
{[n=36]}\end{array}$ & $\begin{array}{c}-10.9 \\
{[\mathrm{n}=20]}\end{array}$ & $\begin{array}{c}-7.2 \\
{[n=130]}\end{array}$ & $\begin{array}{c}-7.5 \\
{[n=130]}\end{array}$ & $\begin{array}{c}-7.9 \\
{[n=87]}\end{array}$ & $\begin{array}{c}-7.6 \\
{[n=166]}\end{array}$ & $\begin{array}{c}-7.6 \\
{[n=166]}\end{array}$ & $\begin{array}{c}-6.4 \\
{[n=180]}\end{array}$ \\
\hline
\end{tabular}

[a] Range: $0-100$, where $0=$ no pain and $100=$ worst pain (Minimal Clinically Important Difference [MCID]: -10 ); [b] Range: $0-10$, where $0=$ no fatigue and $10=$ worst fatigue (MCID: -1$)$; [c] Range: $0-3$, where $0=$ no disability and $3=$ very severe disability (MCID: -0.3 ); [d] Range: $1-81$, where higher scores indicate better physical status (MCID: +2.5); [e] Range: -9-82, where higher scores indicate better mental status (MCID:+2.5);

[f] Range: $0-20$, where lower scores indicate better quality of life; [g] Range: $0-30$, where lower scores

indicate better quality of life (MCID: -5). LOCF: last observation carried forward; OC: observed case.

Sanofi-Aventis, Novartis, AstraZeneca, Janssen, K. Harris Employee of: UCB Pharma, L. Peterson Employee of: UCB Pharma, P. Mease Grant/research support from: (Abbott) AbbVie, Amgen, Bristol-Myers Squibb, Celgene, Janssen, Lilly, Novartis, Pfizer, Sun, UCB Pharma, Consultant for: (Abbott) AbbVie, Amgen, Bristol-Myers Squibb, Celgene, Crescendo, Corrona, Dermira, Janssen, Lilly, Merck, Novartis, Pfizer, Sun, UCB Pharma, Zynerba, Speakers bureau: (Abbott) AbbVie, Amgen, Bristol-Myers Squibb, Celgene, Crescendo, Genentech, Janssen, Novartis, Pfizer, UCB Pharma

DOI: 10.1136/annrheumdis-2017-eular.1654

\section{FRI0490 REAL-LIFE EFFECTIVENESS OF TNF INHIBITORS IN PSORIATIC ARTHRITIS: ARE CHANGING NATIONAL POLICIES ON CHOICE OF TNF INHIBITOR REFLECTED IN RESPONSE TO TREATMENT?}

E.K. Kristianslund ${ }^{1}$, K.M. Fagerli ${ }^{1}$, E. Lie ${ }^{1}$, A. Wierød ${ }^{2}$, S. Kalstad ${ }^{3}$, E. Rødevand ${ }^{4}$, F. Krøl| ${ }^{5}$, P. Mielnik ${ }^{6}$, T.K. Kvien ${ }^{1}$, I.C. Olsen ${ }^{1} .{ }^{1}$ Department of Rheumatology, Diakonhjemmet Hospital, Oslo; ${ }^{2}$ Department of Rheumatology, Drammen Hospital, Drammen; ${ }^{3}$ Department of Rheumatology, University Hospital of North Norway, Tromsø: ${ }^{4}$ Department of Rheumatology, St. Olavs Hospital, Trondheim; ${ }^{5}$ Revmatismesykehuset, Lillehammer; ${ }^{6}$ Department of Rheumatology, Førde Central Hospital, Førde, Norway

Background: Tumour necrosis factor inhibitors (TNFi) are essential in the treatment of psoriatic arthritis (PsA). Whether the effectiveness of the five different TNFi differs is not known, as they have not been directly compared. In Norway the national authorities consider the TNFi to be equivalent, and since 2009 the least expensive drug in an annual national tender has been preferred in the publicly funded healthcare system. This has led to substantial year-to-year differences in chioce of first TNFi, the system has acted as an unbiased factor distributing patients between different agents across years.

Objectives: Comparing response to TNFi during the first year of treatment of PsA over years with highly varying uptake of different TNFi.

Methods: From the NOR-DMARD register we included the 715 biologics-naïve patients with PsA who started their first TNFi from 2009 through 2015. The preferred TNFi in national recommendations were: 2009 adalimumab, 2010 golimumab, 2011 and 2012 etanercept, 2013 golimumab, 2014 certolizumab, 2015 certolizumab/biosimilar infliximab (CT-P13). The estimated Disease Activity Score 28 joints (DAS28) at 3, 6 and 12 months after treatment start was compared between treatment years using a mixed-model, adjusted for baseline disease activity, age, sex and treatment centre.

Results: Demographics, choice of TNFi and baseline characteristics are listed for each year 2009-2015 in Table 1. The preferred drug was started in 56-91\% of patients. There was a trend towards lower disease activity at baseline over time. There were no significant differences in DAS28 at 3 and 6 months between treatment years, but a difference was found at 1 year (figure).

Conclusions: The results from this innovative analytic approach indicate similar effectiveness of different TNFi in PsA, and consequently supports the practice of selecting agent based on cost and feasibility of use. However, there are potential differences after 1 year. The interpretation of this is challenging, especially as there is a marked difference in outcomes between the years 2011 and 2012, where the distribution of type of TNFi was similar. 